\title{
Gallbladder Mucinous Adenocarcinoma
}

National Cancer Institute

\section{Source}

National Cancer Institute. Gallbladder Mucinous Adenocarcinoma. NCI Thesaurus. Code C5744.

An adenocarcinoma that arises from the gallbladder. It is characterized by the presence of extracellular mucin that constitutes more than fifty-percent of the tumor. 